Article

\title{
Environmental Dependence of Artifact CD Peaks of Chiral Schiff Base 3d-4f Complexes in Soft Mater PMMA Matrix
}

\section{Yu Okamoto, Keisuke Nidaira and Takashiro Akitsu *}

Department of Chemistry, Faculty of Science, Tokyo University of Science, 1-3 Kagurazaka, Shinjuku-ku, Tokyo 162-8601, Japan

* Author to whom correspondence should be addressed; E-Mail: akitsu@ rs.kagu.tus.ac.jp; Tel.: +81-3-5228-8271; Fax: +81-3-5261-4631.

Received: 13 September 2011; in revised form: 10 October 2011 / Accepted: 14 October 2011 / Published: 19 October 2011

\begin{abstract}
Four chiral Schiff base binuclear 3d-4f complexes ( $\mathrm{NdNi}, \mathrm{NdCu}, \mathrm{GdNi}$, and $\mathrm{GdCu}$ ) have been prepared and characterized by means of electronic and $\mathrm{CD}$ spectra, IR spectra, magnetic measurements, and X-ray crystallography (NdNi). A so-called artifact peak of solid state CD spectra, which was characteristic of oriented molecules without free molecular rotation, appeared at about $470 \mathrm{~nm}$. Magnetic data of the complexes in the solid state (powder) and in PMMA cast films or solutions indicated that only $\mathrm{GdCu}$ preserved molecular structures in various matrixes of soft maters. For the first time, we have used the changes of intensity of artifact CD peaks to detect properties of environmental (media solid state ( $\mathrm{KBr}$ pellets), PMMA cast films, concentration dependence of PMMA in acetone solutions, and pure acetone solution) for chiral 3d-4f complexes ( $\mathrm{GdCu}$ ). Rigid matrix keeping anisotropic orientation exhibited a decrease in the intensity of the artifact CD peak toward negative values. The present results suggest that solid state artifact CD peaks can be affected by environmental viscosity of a soft mater matrix.
\end{abstract}

Keywords: chirality; solid state CD; soft mater; schiff base complexes

\section{Introduction}

Organic/inorganic hybrid materials containing photochromic organic dyes and transition metal complexes such as models of chiral catalysts [1-3] and magnetic materials [4-8] have been developed 
widely aiming at photo-induced switching systems as supramolecules. As hybrid materials are essentially mixtures, overlapped strong absorption bands of $\pi-\pi *$ and $n-\pi *$ regions make it difficult to deal with individual components generally. To overcome this problem, we employed polarized electronic spectra [9-12] and polarized IR spectra [13,14] in order for selective detection of molecular orientation, or fluorescence spectra [15] as well as absorption spectra. Only CD spectra of chiral components can be observed selectively for hybrid materials of chiral and achiral ones, which show overlapped absorption spectra. Additionally, so-called artifact peaks may sometimes be a serious problem for solid state CD spectra [16-31], in which chiral molecules take anisotropic orientation without a degree of freedom for molecular motion. Although this problem has mainly been dealt with in view of improvement to reduce noise of CD spectra in the solid state, investigation in soft mater matrixes (intermediate between isotropic solutions and anisotropic solids) or positive applications for obtaining useful information have not been carried out so far.

By the way, chiral 3d-4f Schiff base complexes affording interesting structures [32-34] may also be appropriate candidates for distinguishable transitions for separate observation of CD bands. The analogous $3 \mathrm{~d}-4 \mathrm{f}$ complexes have been investigated being focused on magnetic properties $[35,36]$ or emission [37-39] resulting from 4f-electrons of lanthanide ions and their interactions to $3 \mathrm{~d}$ electrons of transiton metal ions. It is well known that detailed treatment of superexchange interactions of $3 \mathrm{~d}-4 \mathrm{f}$ molecule-based magnets is difficult because of spin-orbit interactions except for Gd(III) complexes. In order to overcome this, empirical estimation of magnetic interactions between $3 \mathrm{~d}-4 \mathrm{f}$ ions are sometimes carried out. Although this may also be interesting for chiroptical or other CD spectroscopic studies, few studies have been reported to date.

In this paper, we report on preparations and characterization of new chiral Schiff base binuclear 3d-4f complexes, $\mathrm{NdNi}, \mathrm{NdCu}, \mathrm{GdNi}$, and $\mathrm{GdCu}$ (Figure 1), including optical properties of 3d-4f moieties. We also prepared PMMA cast films containing these complexes and confirmed only the structure of $\mathrm{GdCu}$ was kept by means of magnetic measurement. We measured $\mathrm{CD}$ spectra of $\mathrm{GdCu}$ in a pure acetone, as acetone solutions of PMMA (different concentrations), and in the solid state ( $\mathrm{KBr}$ pellets). Comparison with solid state and complete solution suggested so-called artifact peaks of solid state CD spectrum. As far as we know, we attempt to use the intensity of artifact CD peaks exhibiting environmental dependence of soft mater matrixes for the first time.

Figure 1. Molecular structures of complexes ( $\mathrm{NdNi}, \mathrm{NdCu}, \mathrm{GdNi}$, and $\mathrm{GdCu}$ denote $\mathrm{Ln}$ and $\mathrm{M}$ metal ions). Crystalline water molecules were omitted for clarity.

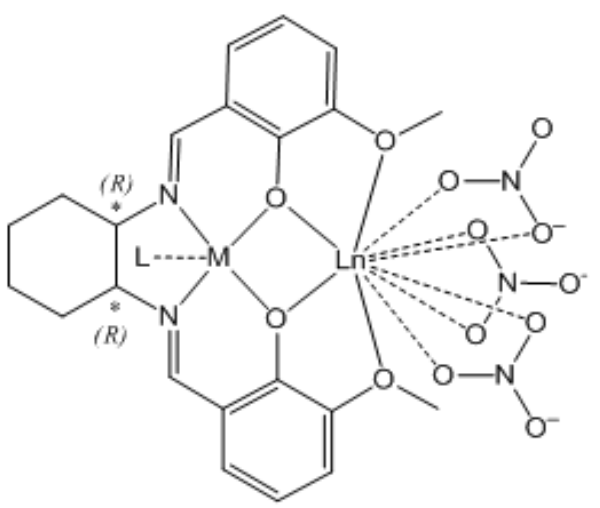




\section{Results and Discussion}

\subsection{Crystal Structure of NdNi}

Typical reactions of Schiff base ligands, 3d (Ni(II) or $\mathrm{Cu}(\mathrm{II})$, and $\mathrm{Zn}(\mathrm{II})$ ) ions, and $4 \mathrm{f}(\mathrm{Nd}(\mathrm{III})$ or $\mathrm{Gd}(\mathrm{III})$ ) ions gave rise to analogous binuclear $3 \mathrm{~d}-4 \mathrm{f}$ complexes [39]. Since $\mathrm{Nd}(\mathrm{III})$ ion can coordinate to this ligand more rigidly than Gd(III) ion generally, which results in different features of crystal growth and dissociation in solutions. As depicted in Figure 2, the crystal structure could be determined only for $\mathrm{NdNi}$ (the other complexes must be similar binuclear structures). Unfortunately, suitable single crystals could not be obtained for other complexes. Asymmetric unit of NdNi contains two crystallographically independent molecules which are coupled with $\pi-\pi$ stacking of ligands by noncovalent interactions. Therefore, intramolecular superexchange interactions between $3 \mathrm{~d}$ and $4 \mathrm{f}$ ions can be expected in view of crystal structures (see later section). $\mathrm{Ni}(\mathrm{II})$ and $\mathrm{Nd}(\mathrm{III})$ ions afford a square planar trans-[ $\left[\mathrm{NiN}_{2} \mathrm{O}_{2}\right]$ and ten-coordinated prism-like $\left[\mathrm{GdO}_{10}\right]$ coordination environment, as summarized in Table 1. Ni(II) ion coordinates no additional axial ligands. Each bond distance and angle of the ligand moieties including cyclohexyl groups connected to asymmetric carbon atoms of $(R, R)$-configuration are within normal values for analogous Schiff base complexes [32,33,39].

Figure 2. Crystal structures of $\mathrm{NdNi}$ showing selected atom labeling scheme. Hydrogen atoms are omitted clarity.

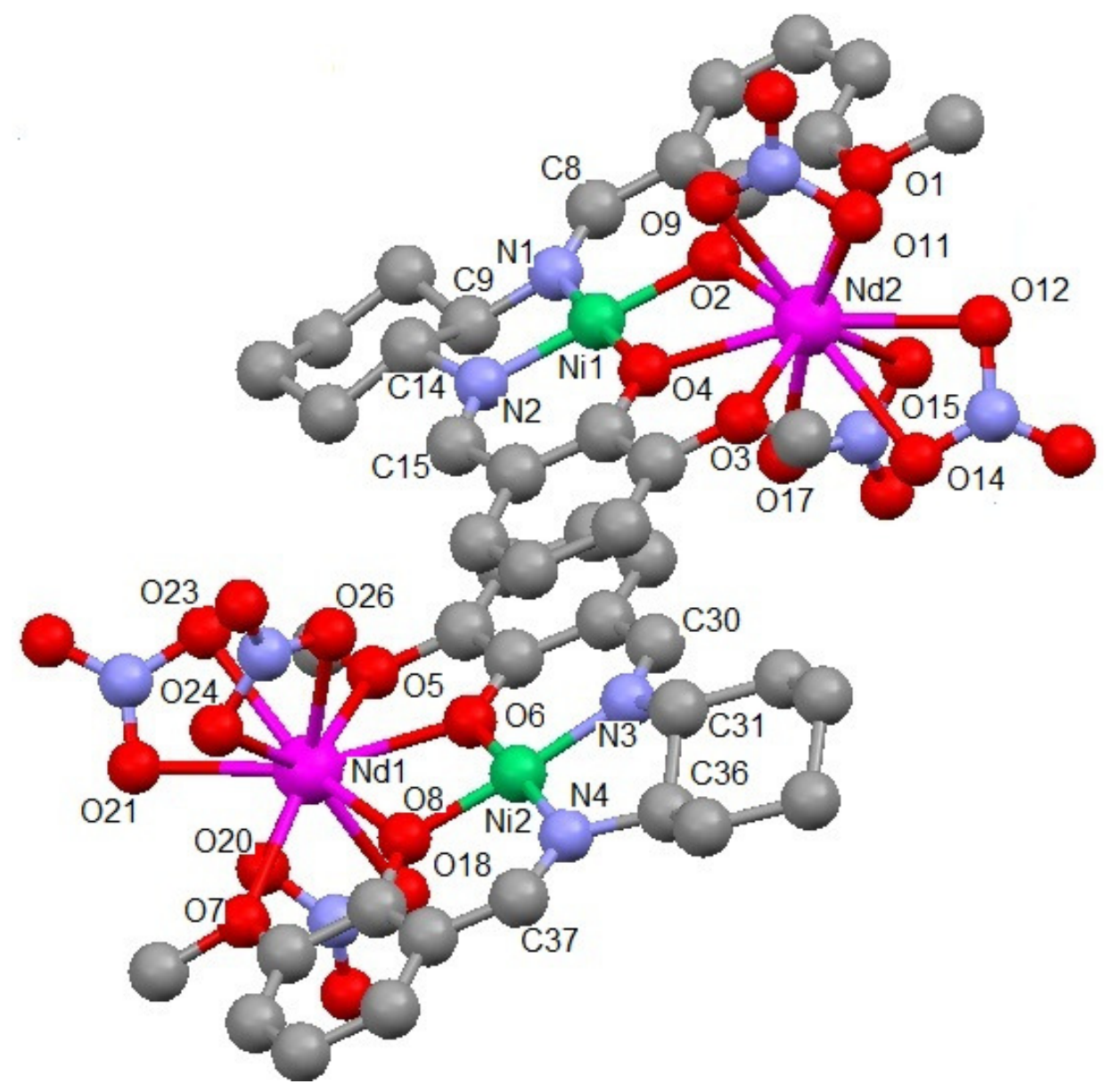


Table 1. Selected bond distance $(\AA)$ and angles $\left(^{\circ}\right)$ of NdNi.

\begin{tabular}{|c|c|c|c|}
\hline $\mathrm{Nd} 1-\mathrm{O} 6=2.374(7)$ & $\mathrm{Nd} 1-\mathrm{O} 8=2.377(6)$ & $\mathrm{Nd} 1-\mathrm{O} 20=2.468(8)$ & Nd1-O18 = 2.470(7) \\
\hline $\mathrm{Nd} 1-\mathrm{O} 23=2.477(7)$ & $\mathrm{Nd} 1-\mathrm{O} 21=2.482(7)$ & $\mathrm{Nd} 1-\mathrm{O} 26=2.510(7)$ & $\mathrm{Nd} 1-\mathrm{O} 24=2.514(7)$ \\
\hline $\mathrm{Nd} 1-\mathrm{O} 5=2.528(6)$ & $\mathrm{Nd} 1-\mathrm{O} 7=2.543(6)$ & $\mathrm{Nd} 1-\mathrm{N} 8=2.873(8)$ & Nd1-N9 = 2.902(8) \\
\hline $\mathrm{Nd} 2-\mathrm{O} 2=2.337(7)$ & $\mathrm{Nd} 2-\mathrm{O} 4=2.395(7)$ & $\mathrm{Nd} 2-\mathrm{O} 11=2.463(9)$ & $\mathrm{Nd} 2-\mathrm{O} 9=2.478(7)$ \\
\hline $\mathrm{Nd} 2-\mathrm{O} 15=2.504(7)$ & $\mathrm{Nd} 2-\mathrm{O} 1=2.507(6)$ & $\mathrm{Nd} 2-\mathrm{O} 14=2.518(6)$ & $\mathrm{Nd} 2-\mathrm{O} 3=2.522(7)$ \\
\hline $\mathrm{Nd} 2-\mathrm{O} 12=2.523(7)$ & $\mathrm{Nd} 2-\mathrm{O} 17=2.533(9)$ & Nd2-N5 = 2.921(11) & $\mathrm{Nd} 2-\mathrm{N} 7=2.942(9)$ \\
\hline $\mathrm{Ni1}-\mathrm{O} 4=1.838(6)$ & $\mathrm{Ni1}-\mathrm{N} 2=1.843(7)$ & Ni1-N1 $=1.844(8)$ & $\mathrm{Ni1}-\mathrm{O} 2=1.876(7)$ \\
\hline $\mathrm{Ni} 2-\mathrm{O} 8=1.833(6)$ & $\mathrm{Ni2}-\mathrm{N} 4=1.849(8)$ & $\mathrm{Ni2}-\mathrm{N} 3=1.855(8)$ & $\mathrm{Ni2}-\mathrm{O} 6=1.861(7)$ \\
\hline O4-Ni1-N2 = 94.3(3) & O4-Ni1-N1 = 175.9(3) & N2-Ni1-N1 = 88.7(3) & O4-Ni1-O2 = 81.9(3) \\
\hline $\mathrm{N} 2-\mathrm{Ni1}-\mathrm{O} 2=175.8(3)$ & $\mathrm{N} 1-\mathrm{Ni1}-\mathrm{O} 2=95.2(3)$ & O8-Ni2-N4 = 95.3(3) & O8-Ni2-N3 = 175.7(3) \\
\hline N4-Ni2-N3 = 85.9(3) & O8-Ni2-O6 = 82.8(3) & N4-Ni2-O6 = 175.3(3) & N3-Ni2-O6 = 96.3(3) \\
\hline O6-Nd1-O8 = 61.9(2) & O6-Nd1-O20 = 117.0(3) & O8-Nd1-O20 = 118.6(2) & O6-Nd1-O18 = 73.6(3) \\
\hline O8-Nd1-O18 = 74.9(2) & $\mathrm{O} 20-\mathrm{Nd} 1-\mathrm{O} 18=51.4(3)$ & O6-Nd1-O23 = 110.7(2) & $\mathrm{O} 8-\mathrm{Nd} 1-\mathrm{O} 23=144.0(2)$ \\
\hline $\mathrm{O} 20-\mathrm{Nd} 1-\mathrm{O} 23=96.5(2)$ & $\mathrm{O} 18-\mathrm{Nd} 1-\mathrm{O} 23=139.6(2)$ & O6-Nd1-O21 = 161.2(2) & $\mathrm{O} 8-\mathrm{Nd} 1-\mathrm{O} 21=134.3(2)$ \\
\hline $\mathrm{O} 20-\mathrm{Nd} 1-\mathrm{O} 21=66.8(3)$ & $\mathrm{O} 18-\mathrm{Nd} 1-\mathrm{O} 21=116.6(3)$ & $\mathrm{O} 23-\mathrm{Nd} 1-\mathrm{O} 21=51.0(2)$ & $\mathrm{O} 6-\mathrm{Nd} 1-\mathrm{O} 26=68.1(2)$ \\
\hline $\mathrm{O} 8-\mathrm{Nd} 1-\mathrm{O} 26=77.1(2)$ & $\mathrm{O} 20-\mathrm{Nd} 1-\mathrm{O} 26=164.3(2)$ & $\mathrm{O} 18-\mathrm{Nd} 1-\mathrm{O} 26=139.9(2)$ & $\mathrm{O} 23-\mathrm{Nd} 1-\mathrm{O} 26=68.1(2)$ \\
\hline $\mathrm{O} 21-\mathrm{Nd} 1-\mathrm{O} 26=103.5(2)$ & O6-Nd1-O24 = 111.9(2) & $\mathrm{O} 8-\mathrm{Nd} 1-\mathrm{O} 24=77.6(2)$ & O20-Nd1-O24 = 130.3(2) \\
\hline O18-Nd1-O24 = 144.6(2) & $\mathrm{O} 23-\mathrm{Nd} 1-\mathrm{O} 24=73.3(2)$ & $\mathrm{O} 21-\mathrm{Nd} 1-\mathrm{O} 24=69.8(3)$ & $\mathrm{O} 26-\mathrm{Nd} 1-\mathrm{O} 24=50.2(2)$ \\
\hline O6-Nd1-O5 = 63.2(2) & $\mathrm{O} 8-\mathrm{Nd} 1-\mathrm{O} 5=124.0(2)$ & $\mathrm{O} 20-\mathrm{Nd} 1-\mathrm{O} 5=78.2(2)$ & $\mathrm{O} 18-\mathrm{Nd} 1-\mathrm{O} 5=80.4(2)$ \\
\hline $\mathrm{O} 23-\mathrm{Nd} 1-\mathrm{O} 5=68.0(2)$ & $\mathrm{O} 21-\mathrm{Nd} 1-\mathrm{O} 5=101.7(2)$ & $\mathrm{O} 26-\mathrm{Nd} 1-\mathrm{O} 5=92.4(2)$ & $\mathrm{O} 24-\mathrm{Nd} 1-\mathrm{O} 5=134.3(2)$ \\
\hline O6-Nd1-O7 = 123.8(2) & O8-Nd1-O7 = 64.4(2) & $\mathrm{O} 20-\mathrm{Nd} 1-\mathrm{O} 7=76.1(2)$ & O18-Nd1-O7 = 77.9(2) \\
\hline $\mathrm{O} 23-\mathrm{Nd} 1-\mathrm{O} 7=122.2(2)$ & $\mathrm{O} 21-\mathrm{Nd} 1-\mathrm{O} 7=74.8(2)$ & $\mathrm{O} 26-\mathrm{Nd} 1-\mathrm{O} 7$ = 114.3(2) & $\mathrm{O} 24-\mathrm{Nd} 1-\mathrm{O} 7=70.2(2)$ \\
\hline O5-Nd1-O7 = 153.2(2) & O6-Nd1-N8 = 97.3(2) & O8-Nd1-N8 = 95.4(2) & $\mathrm{O} 20-\mathrm{Nd} 1-\mathrm{N} 8=25.7(2)$ \\
\hline O18-Nd1-N8 = 26.1(3) & $\mathrm{O} 23-\mathrm{Nd} 1-\mathrm{N} 8=120.5(2)$ & O21-Nd1-N8 = 90.8(2) & $\mathrm{O} 26-\mathrm{Nd} 1-\mathrm{N} 8=165.4(2)$ \\
\hline O24-Nd1-N8 = 141.1(2) & O5-Nd1-N8 = 81.3(2) & $\mathrm{O} 7-\mathrm{Nd} 1-\mathrm{N} 8=72.3(2)$ & O6-Nd1-N9 = 137.1(2) \\
\hline O8-Nd1-N9 = 145.1(2) & $\mathrm{O} 20-\mathrm{Nd} 1-\mathrm{N} 9=81.6(2)$ & O18-Nd1-N9 = 132.8(3) & $\mathrm{O} 23-\mathrm{Nd} 1-\mathrm{N} 9=26.4(2)$ \\
\hline $\mathrm{O} 21-\mathrm{Nd} 1-\mathrm{N} 9=24.6(2)$ & $\mathrm{O} 26-\mathrm{Nd} 1-\mathrm{N} 9=85.2(2)$ & $\mathrm{O} 24-\mathrm{Nd} 1-\mathrm{N} 9=68.0(2)$ & O5-Nd1-N9 = 86.1(2) \\
\hline O7-Nd1-N9 = 97.3(2) & N8-Nd1-N9 = 107.3(2) & $\mathrm{O} 2-\mathrm{Nd} 2-\mathrm{O} 4=61.9(2)$ & $\mathrm{O} 2-\mathrm{Nd} 2-\mathrm{O} 11=119.4(3)$ \\
\hline O4-Nd2-O11 = 118.3(3) & $\mathrm{O} 2-\mathrm{Nd} 2-\mathrm{O} 9=76.9(2)$ & $\mathrm{O} 4-\mathrm{Nd} 2-\mathrm{O} 9=72.9(3)$ & $\mathrm{O} 11-\mathrm{Nd} 2-\mathrm{O} 9=52.0(3)$ \\
\hline $\mathrm{O} 2-\mathrm{Nd} 2-\mathrm{O} 15=79.1(2)$ & $\mathrm{O} 4-\mathrm{Nd} 2-\mathrm{O} 15=114.1(2)$ & $\mathrm{O} 11-\mathrm{Nd} 2-\mathrm{O} 15=127.0(3)$ & O9-Nd2-O15 = 147.3(2) \\
\hline $\mathrm{O} 2-\mathrm{Nd} 2-\mathrm{O} 1=62.8(2)$ & $\mathrm{O} 4-\mathrm{Nd} 2-\mathrm{O} 1=121.8(2)$ & $\mathrm{O} 11-\mathrm{Nd} 2-\mathrm{O} 1=75.8(3)$ & $\mathrm{O} 9-\mathrm{Nd} 2-\mathrm{O} 1=78.6(2)$ \\
\hline $\mathrm{O} 15-\mathrm{Nd} 2-\mathrm{O} 1=70.7(2)$ & $\mathrm{O} 2-\mathrm{Nd} 2-\mathrm{O} 14=141.3(3)$ & $\mathrm{O} 4-\mathrm{Nd} 2-\mathrm{O} 14=111.1(2)$ & $\mathrm{O} 11-\mathrm{Nd} 2-\mathrm{O} 14=97.8(3)$ \\
\hline O9-Nd2-O14 = 140.3(2) & $\mathrm{O} 15-\mathrm{Nd} 2-\mathrm{O} 14=69.5(2)$ & $\mathrm{O} 1-\mathrm{Nd} 2-\mathrm{O} 14=122.9(2)$ & $\mathrm{O} 2-\mathrm{Nd} 2-\mathrm{O} 3=123.2(2)$ \\
\hline $\mathrm{O} 4-\mathrm{Nd} 2-\mathrm{O} 3=61.9(2)$ & $\mathrm{O} 11-\mathrm{Nd} 2-\mathrm{O} 3=81.3(3)$ & $\mathrm{O} 9-\mathrm{Nd} 2-\mathrm{O} 3=79.7(3)$ & $\mathrm{O} 15-\mathrm{Nd} 2-\mathrm{O} 3=132.5(2)$ \\
\hline O1-Nd2-O3 = 155.2(2) & $\mathrm{O} 14-\mathrm{Nd} 2-\mathrm{O} 3=69.5(2)$ & $\mathrm{O} 2-\mathrm{Nd} 2-\mathrm{O} 12=134.9(2)$ & O4-Nd2-O12 = 160.91(19) \\
\hline $\mathrm{O} 11-\mathrm{Nd} 2-\mathrm{O} 12=65.1(3)$ & O9-Nd2-O12 = 116.2(3) & $\mathrm{O} 15-\mathrm{Nd} 2-\mathrm{O} 12=68.2(3)$ & $\mathrm{O} 1-\mathrm{Nd} 2-\mathrm{O} 12=77.2(2)$ \\
\hline $\mathrm{O} 14-\mathrm{Nd} 2-\mathrm{O} 12=50.7(2)$ & $\mathrm{O} 3-\mathrm{Nd} 2-\mathrm{O} 12=101.9(2)$ & $\mathrm{O} 2-\mathrm{Nd} 2-\mathrm{O} 17=74.6(3)$ & $\mathrm{O} 4-\mathrm{Nd} 2-\mathrm{O} 17=67.3(3)$ \\
\hline O11-Nd2-O17 = 166.0(3) & O9-Nd2-O17 = 138.5(3) & $\mathrm{O} 15-\mathrm{Nd} 2-\mathrm{O} 17=51.6(2)$ & $\mathrm{O} 1-\mathrm{Nd} 2-\mathrm{O} 17=113.1(3)$ \\
\hline O14-Nd2-O17 = 68.3(3) & $\mathrm{O} 3-\mathrm{Nd} 2-\mathrm{O} 17=91.3(3)$ & $\mathrm{O} 12-\mathrm{Nd} 2-\mathrm{O} 17=105.3(2)$ & $\mathrm{O} 2-\mathrm{Nd} 2-\mathrm{N} 5=96.9(3)$ \\
\hline O4-Nd2-N5 = 95.2(3) & $\mathrm{O} 11-\mathrm{Nd} 2-\mathrm{N} 5=27.2(3)$ & O9-Nd2-N5 = 24.8(3) & $\mathrm{O} 15-\mathrm{Nd} 2-\mathrm{N} 5=143.0(3)$ \\
\hline O1-Nd2-N5 = 74.8(3) & O14-Nd2-N5 = 121.8(3) & O3-Nd2-N5 = 80.5(3) & O12-Nd2-N5 = 91.6(3) \\
\hline O17-Nd2-N5 = 162.5(3) & $\mathrm{O} 2-\mathrm{Nd} 2-\mathrm{N} 7=76.9(2)$ & $\mathrm{O} 4-\mathrm{Nd} 2-\mathrm{N} 7=92.1(3)$ & O11-Nd2-N7 = 149.4(3) \\
\hline O9-Nd2-N7 = 153.6(2) & $\mathrm{O} 15-\mathrm{Nd} 2-\mathrm{N} 7=25.0(3)$ & $\mathrm{O} 1-\mathrm{Nd} 2-\mathrm{N} 7=92.0(3)$ & O14-Nd2-N7 = 65.1(2) \\
\hline $\mathrm{O} 3-\mathrm{Nd} 2-\mathrm{N} 7=112.7(2)$ & $\mathrm{O} 12-\mathrm{Nd} 2-\mathrm{N} 7=85.0(2)$ & O17-Nd2-N7 = 26.7(3) & \\
\hline
\end{tabular}




\subsection{Magnetic Properties}

Figures $3 \mathrm{~A}$ and Figure 3B show the $\chi_{M} T$ vs $T$ plots of $\mathrm{Nd}(\mathrm{III})(\mathrm{NdNi}$ and $\mathrm{NdCu})$ and $\mathrm{Gd}(\mathrm{III})(\mathrm{GdNi}$ and $\mathrm{GdCu})$ complexes including the differences of $\chi_{M} T$ values $\left(\chi_{M} T(\mathrm{NdCu})-\chi_{M} T(\mathrm{NdNi})\right.$ and $\left.\chi_{M} T(\mathrm{GdCu})-\chi_{M} T(\mathrm{GdNi})\right)$. As the data at $300 \mathrm{~K}$ suggested, $\mathrm{Cu}(\mathrm{II})$ ion and $\mathrm{Ni}$ (II) ion of four-coordinated square planar coordination environment are $S=1 / 2$ (paramagnetic) and $S=0$ (diamagnetic), respectively. The ground electronic state of $\mathrm{Nd}(\mathrm{III})$ ion is ${ }^{4} \mathrm{I} 9 / 2$ with $\mathrm{S}=3 / 2, \mathrm{~L}=6, \mathrm{~J}=9 / 2$ with $\lambda=290 \mathrm{~cm}^{-1}$, while that of $\mathrm{Gd}(\mathrm{III})$ ion is ${ }^{8} \mathrm{~S}_{7 / 2}$ with $\mathrm{S}=7 / 2, \mathrm{~L}=0, \mathrm{~J}=7 / 2$ with $\lambda=0 \mathrm{~cm}^{-1}$, the total orbital angular momentum is zero and single ion anisotropy due to spin-orbit interaction should be negligible. Therefore, empirical proof of ferromagnetic superexchange interaction based on the differences of $\chi_{M} T$ values may be clear and reliable. Actually, the corresponding data of $\mathrm{Nd}$ (III) complexes $\left(\chi_{M} T(\mathrm{NdCu})-\chi_{M} T(\mathrm{NdNi})\right)$ did not exhibit increasing of low-temperature region, while that of Gd(III) complexes $\left(\chi_{M} T(\mathrm{GdCu})-\chi_{M} T(\mathrm{GdNi})\right)$ exhibited typical peak in the low-temperature region. Therefore, the $3 \mathrm{~d}-4 \mathrm{f}$ binuclear moiety of $\mathrm{GdCu}$ can be judged to be ferromagnetic one.

Figure 3C shows comparison of the $\chi_{M} T$ vs $T$ plots of $\mathrm{GdCu}$ as a bulk powder sample (identical to the data above) and $\mathrm{GdCu}$ as PMMA cast films. Contrary to other three complexes (not shown), only $\mathrm{GdCu}$ exhibited similar behavior regardless of bulk and film except for increasing of diamagnetic contribution of PMMA in the high-temperature region. The results suggest that coordination of lanthanide ion is kept only for $\mathrm{GdCu}$. In this way, $\mathrm{GdCu}$ is suitable for the flowing discussion associated with CD spectroscopy because of these two conditions, namely, ferromagnetic interaction and rigidity of $\mathrm{Gd}(\mathrm{III})$ ion coordination.

Figure 3. (A) The $\chi_{M} T$ vs $T$ plots for $\mathrm{NdNi}$ and $\mathrm{NdCu}$ as powder and the differences of $\chi_{\mathrm{M}} \mathrm{T}(\mathrm{NdCu}-\mathrm{NdNi})$ at $0.5 \mathrm{~T}$; (B) The $\chi_{M} T$ vs $T$ plots for $\mathrm{GdNi}$ and $\mathrm{GdCu}$ as powder and the differences of $\chi_{\mathrm{M}} \mathrm{T}(\mathrm{GdCu}-\mathrm{GdNi})$ at $0.5 \mathrm{~T} ;(\mathbf{C})$ The $\chi_{M} T$ vs $T$ plots for $\mathrm{GdCu}$ as powder and as a PMMA cast film at $0.5 \mathrm{~T}$.

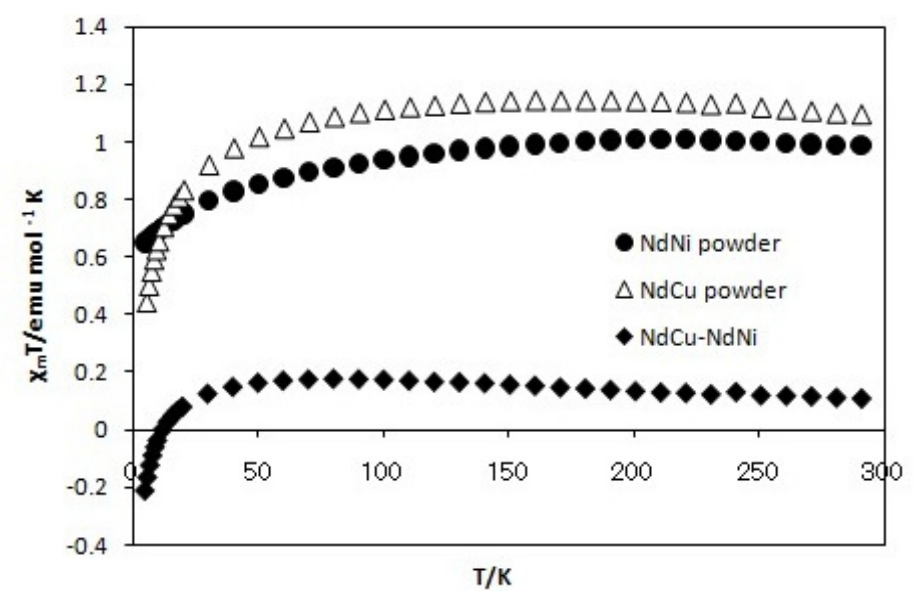

(A) 
Figure 3. Cont.

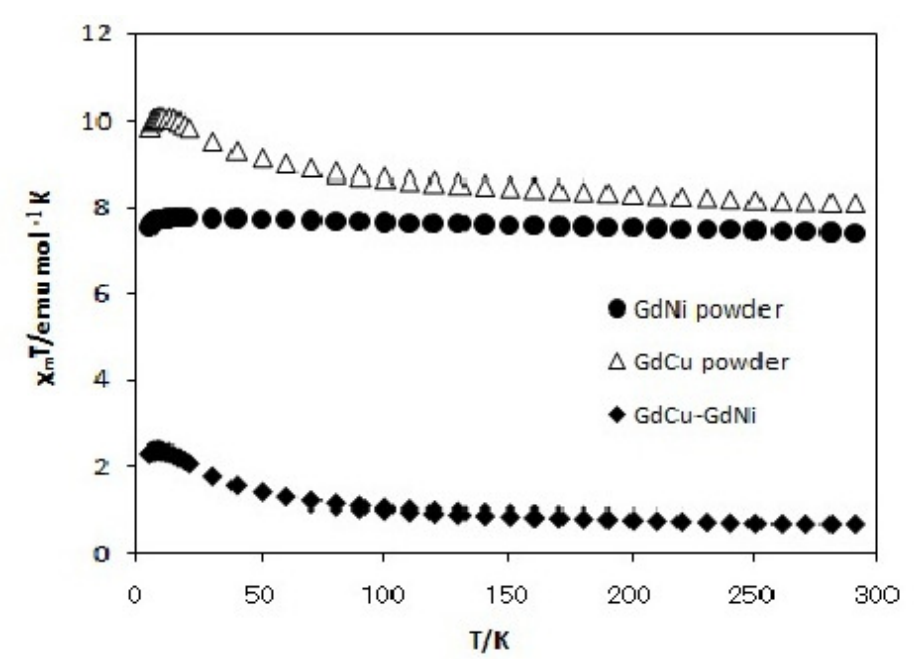

(B)

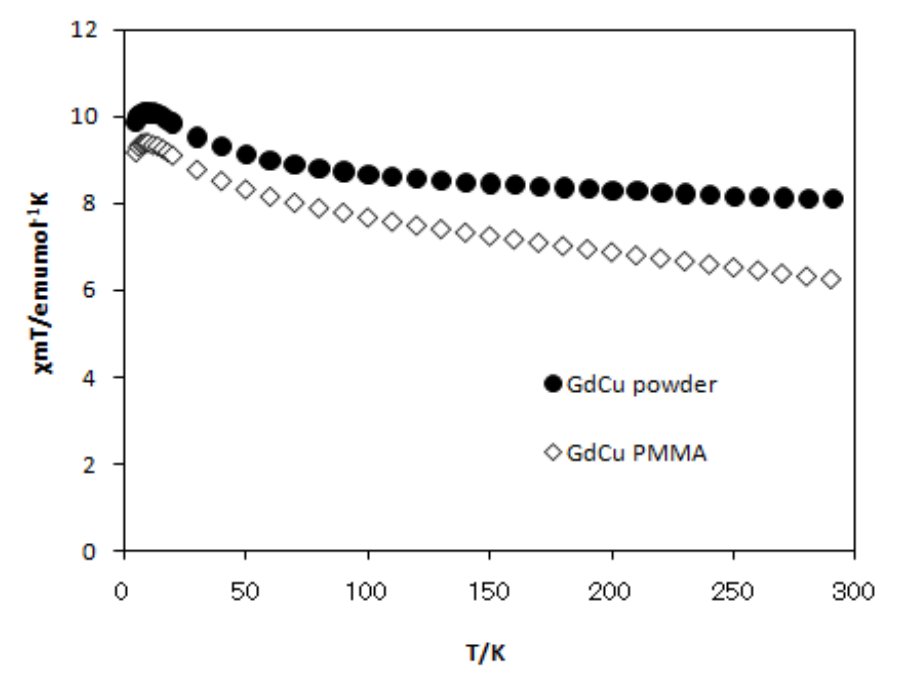

(C)

\subsection{Spectra in the Solid State}

Figures 4 and 5 show solid state CD spectra and the corresponding diffuse reflectance electronic spectra of $\mathrm{Ni}(\mathrm{II})$ complexes $(\mathrm{NdNi}, \mathrm{GdNi}$, and the related mononuclear $\mathrm{Ni}$ complex having the identical chiral ligand) and $\mathrm{Cu}(\mathrm{II})$ complexes $(\mathrm{NdCu}, \mathrm{GdCu}$, and mononuclear $\mathrm{Cu}$ ), respectively. The different features of $\mathrm{d}-\mathrm{d}$ band around 500-600 $\mathrm{nm}$ for mononuclear $\mathrm{Ni}$ and $\mathrm{Cu}$ complexes are ascribed to conventional difference of square planar Schiff base $\mathrm{Ni}(\mathrm{II})$ and $\mathrm{Cu}$ (II) complexes. Indeed, the signs of the corresponding $\mathrm{CD}$ bands are opposite. When $\mathrm{Nd}(\mathrm{III})$ ions are introduced, sharp f-f peaks appeared at 580, 740, and $790 \mathrm{~nm}$ in the diffuse reflectance electronic spectra. When Nd(III) or Gd(III) ions are introduced or replaced, the region of charge transfer bands are affected predominantly. The corresponding CD bands are changed; in particular, the region of 500-550 nm for $\mathrm{Ni}$ (II) complexes exhibited clear shifts, which is not clear in the diffuse reflectance electronic spectra. When comparing this with the CD spectra in solutions (in which free molecular motion is permitted), so-called artifact $\mathrm{CD}$ peaks in the solid state (in which molecular motion is not permitted completely) can be assigned to 
the peaks around $470 \mathrm{~nm}$, which is neighboring region of d-d bands around 500-600 nm and an important region for chiroptical features of binuclear 3d-4f systems.

Figure 4. The $\mathrm{CD}$ and diffuse reflectance electronic spectra of $\mathrm{NdNi}$ and GdNi (and the corresponding mononuclear Ni complex for comparison) measured as $\mathrm{KBr}$ pellets.
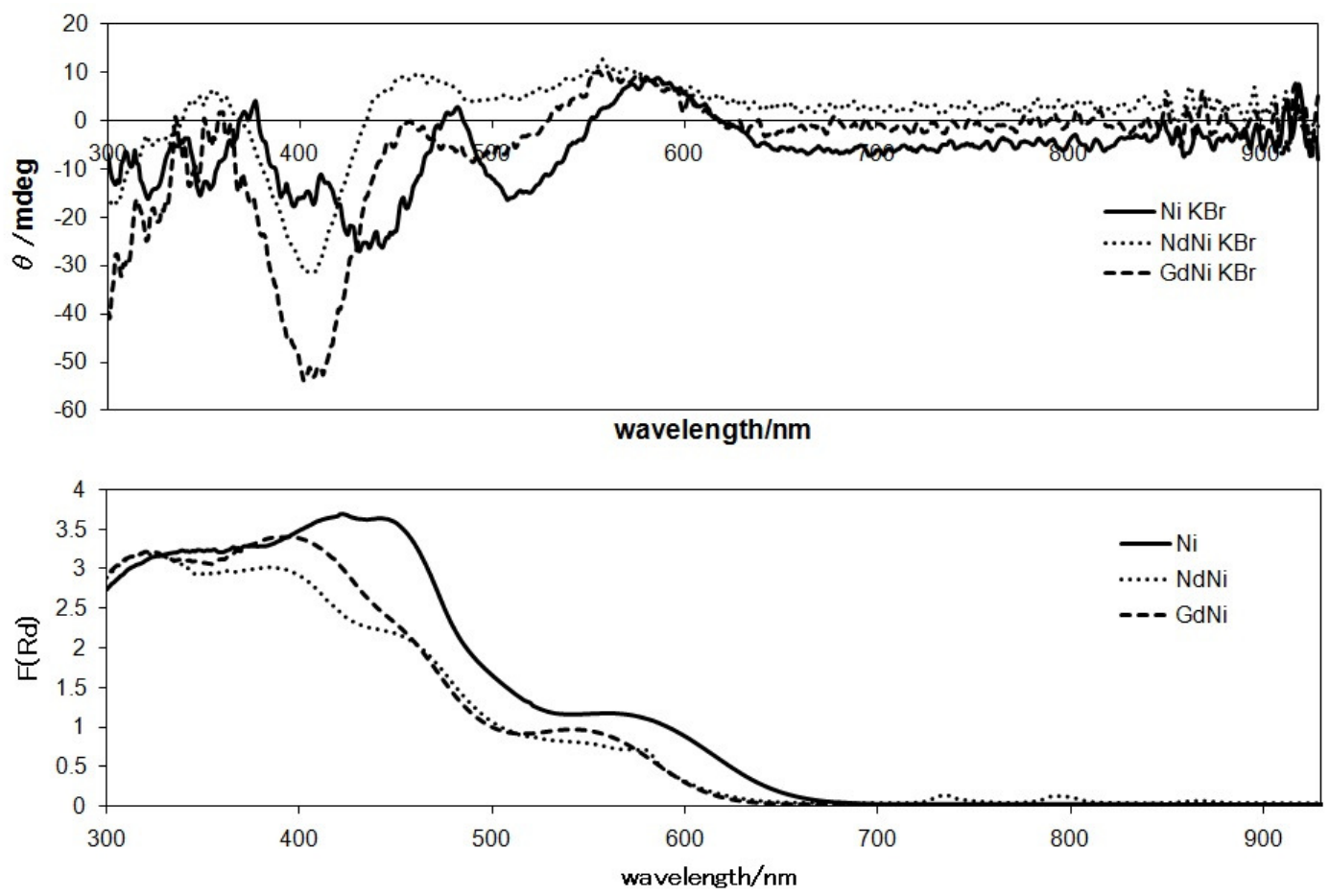

Figure 5. The $\mathrm{CD}$ and diffuse reflectance electronic spectra of $\mathrm{NdCu}$ and $\mathrm{GdCu}$ (and the corresponding mononuclear $\mathrm{Cu}$ complex for comparison) measured as $\mathrm{KBr}$ pellets.
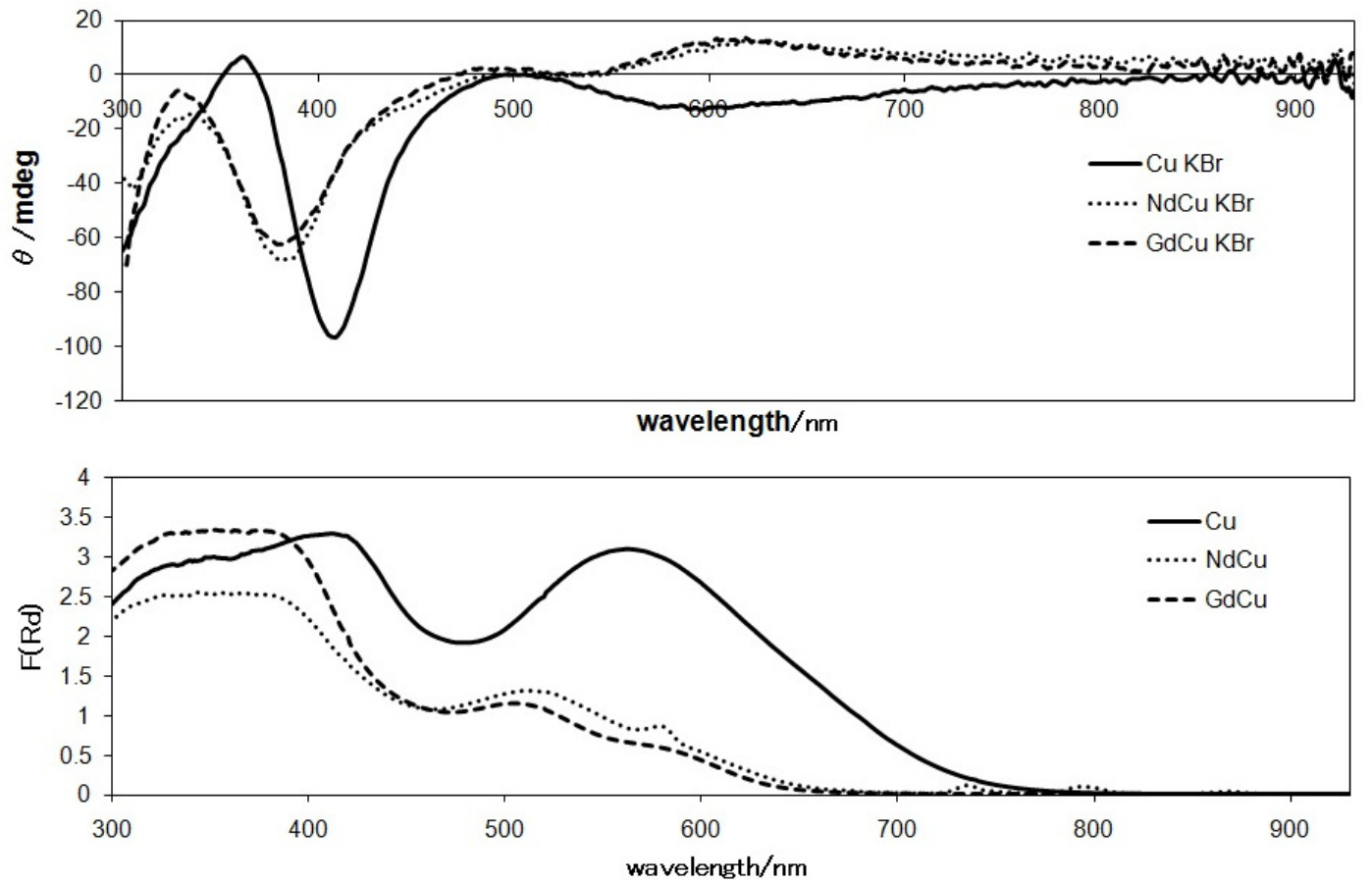


\subsection{Spectra in PMMA Films or Solutions}

Figure $6 \mathrm{~B}$ shows the $\mathrm{CD}$ and the corresponding electronic absorption spectra of $\mathrm{GdCu}$ measured as PMMA cast films, PMMA acetone solutions of various concentration (mass\%), and acetone solution. PMMA cast film is a novel environment, having flexibility in which molecular orientation can be kept and simultaneously molecular motion (conformational changes) can be permitted. Furthermore, acetone solutions with a high concentration of PMMA lose its freedom of molecular motion. In these solutions, anisotropy of molecular orientation gradually may be increased to appear so-called artifact CD peaks, which is ascribed to losing isotropy of molecular orientation in rigid environment of a matrix. Little changes of the corresponding electronic absorption spectra also support that spectral changes of $\mathrm{CD}$ spectra are essentially ascribed to not reactions or changes of molecules but the principle of CD spectroscopy.

Figure 6A is magnification of the CD spectra (Figure 6B). It indicates concentration or viscositydependence of the $\mathrm{CD}$ spectra of PMMA acetone solutions of $\mathrm{GdCu}$. As PMMA cast film and solutions, intensity changes (negative decreasing of $\theta$ values) with a CD peak around $470 \mathrm{~nm}$ assigned as an artifact $\mathrm{CD}$ peak of solid state indicated, depending on viscosity of matrix. In this way, the intensity of so-called artifact peaks is changed as the degree of restriction of molecular motion in correlation with concentration of viscous PMMA concentration or environment of a soft mater or complete solid state.

Figure 6. (A) Concentration (viscosity) dependence of the CD spectra of PMMA film, PMMA acetone solutions, and acetone solution of $\mathrm{GdCu}$ (magnified); (B) Concentration (viscosity) dependence of $\mathrm{CD}$ and the corresponding electronic absorption spectra of PMMA film, PMMA acetone solutions, and acetone solution of $\mathrm{GdCu}$.

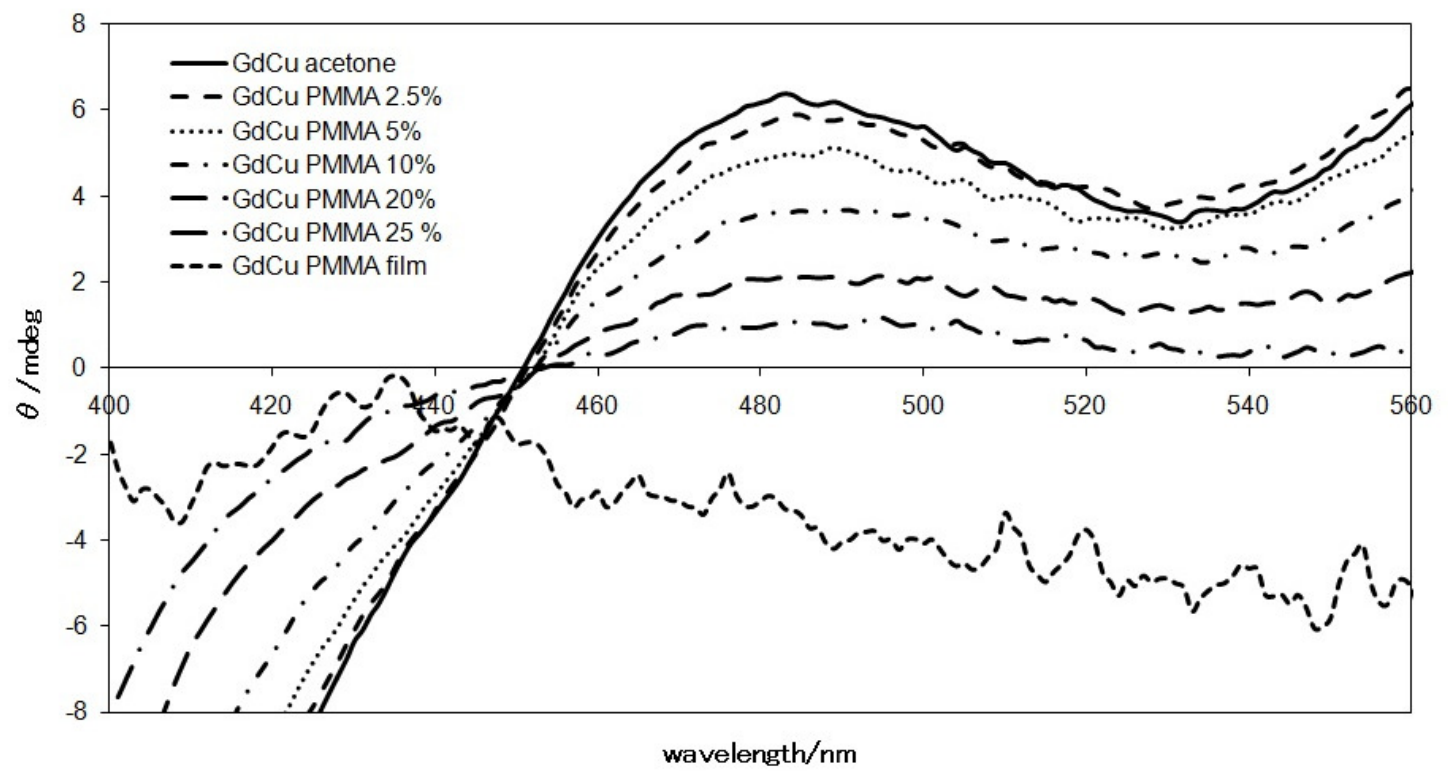

(A) 
Figure 6. Cont.
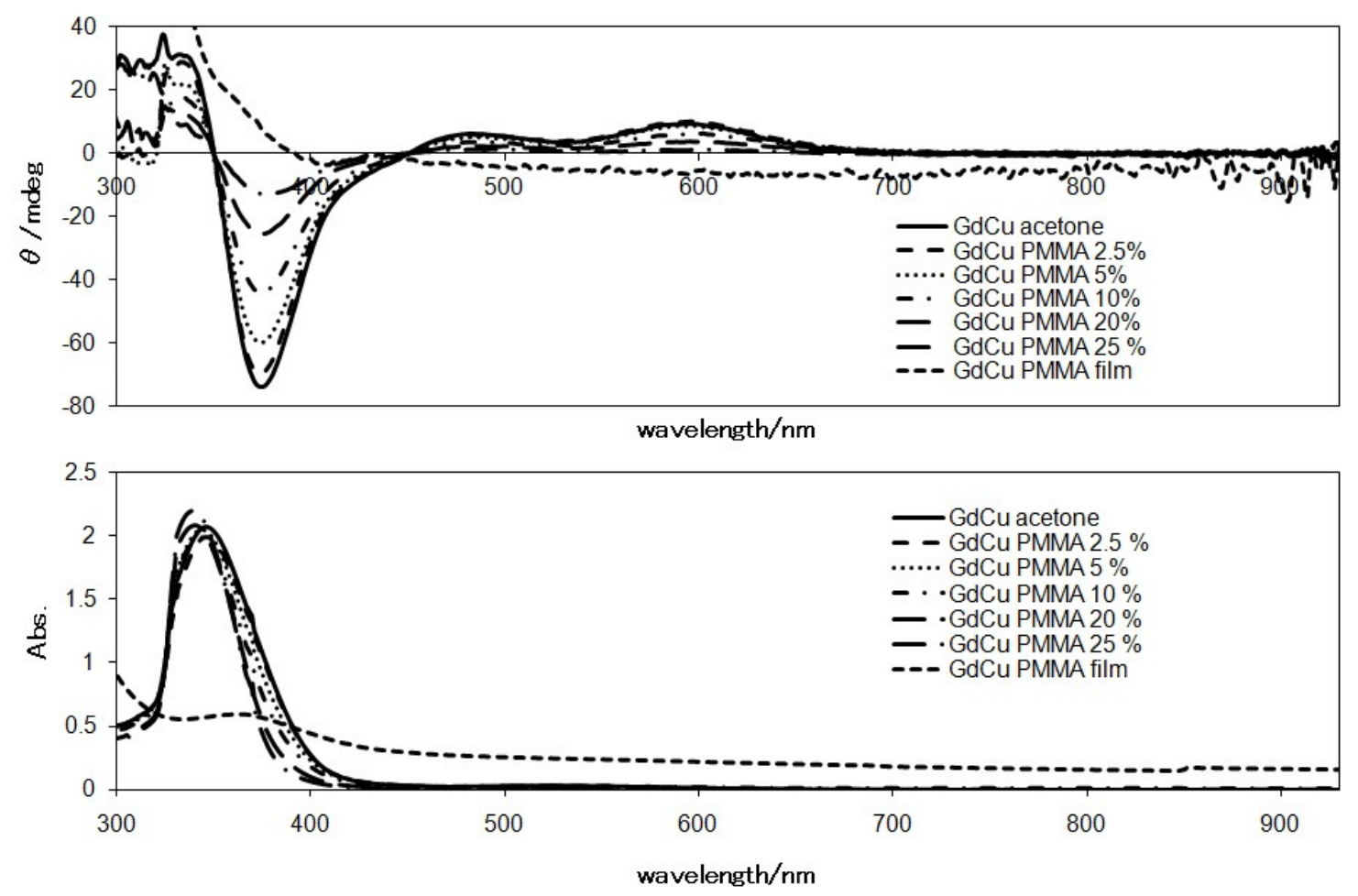

(B)

\section{Experimental Section}

\subsection{General Procedures}

Chemicals of the highest commercial grade available (solvents from Kanto Chemical, organic compounds from Tokyo Chemical Industry and metal sources from Wako) were used as received without further purification.

\subsection{Preparations}

\subsubsection{Preparation of $\mathrm{NdNi}$}

To a solution of $o$-vanillin $(0.3069 \mathrm{~g}, 2.00 \mathrm{mmol})$ dissolved in methanol (40 $\mathrm{mL})$, $(1 R, 2 R)-(-)-1,2$-cyclohexandiamine $(0.1231 \mathrm{~g}, 1.00 \mathrm{mmol})$ was added dropwise and stirred at $313 \mathrm{~K}$ for $2 \mathrm{~h}$ to give yellow solution of ligand. Nickel(II) acetate tetrahydrate $(0.2493 \mathrm{~g}, 1.00 \mathrm{mmol})$ was added to give rise to orange solution of the complex. After stirring for $2 \mathrm{~h}$, neodymium (III) nitrate hexahydrate $(0.4552 \mathrm{~g}, 1.00 \mathrm{mmol})$ was added and refluxed at $373 \mathrm{~K}$ for $4 \mathrm{~h}$ to yield orange solution with orange precipitates. This crude orange compound was filtered and recrystallized from methanol/diethyl ether to give orange prismatic single crystals suitable for X-ray analysis containing solvents. Yield $0.5804 \mathrm{~g}(89.9 \%)$. IR $\left(\mathrm{KBr}\left(\mathrm{cm}^{-1}\right)\right)$ : 451, 565, 667, 740, 748, 785, 856, 965, 1031, 1078, 1166, 1232, 1307, 1381, 1468, 1624(C=N), 1652, 1699, 2413, 2848, 2927. UV-vis (nm (Abs)): (acetone) 332 (0.96). (methanol) 331 (0.46). (chloroform) 339 (0.73). CD (nm ( $\theta / \mathrm{mdeg})$ ): (acetone) 
394 (-25.5), 450 (4.66), 568 (5.47). (methanol) 391 (-10.2), 456 (1.22), 559 (3.13). (chloroform) 404 (-5.42), 459 (1.03), $566(1.51)$.

\subsubsection{Preparation of $\mathrm{NdCu}$}

To a solution of $o$-vanillin $(0.3054 \mathrm{~g}, 2.00 \mathrm{mmol})$ dissolved in methanol $(40 \mathrm{~mL})$, $(1 R, 2 R)-(-)-1,2$-cyclohexandiamine $(0.1171 \mathrm{~g}, 1.00 \mathrm{mmol})$ was added dropwise and stirred at $313 \mathrm{~K}$ for $2 \mathrm{~h}$ to give yellow solution of ligand. Copper (II) acetate monohydrate $(0.2048 \mathrm{~g}, 1.00 \mathrm{mmol})$ was added to give rise to purple-red solution of the complex. After stirring for $2 \mathrm{~h}$, neodymium (III) nitrate hexahydrate $(0.4493 \mathrm{~g}, 1.00 \mathrm{mmol})$ was added and refluxed at $373 \mathrm{~K}$ for $4 \mathrm{~h}$ to yield red solution with red precipitates. This crude red compound was filtered and recrystallized from methanol/diethyl ether to give red precipitates. Yield $0.6333 \mathrm{~g}(97.4 \%)$. IR $\left(\mathrm{KBr}\left(\mathrm{cm}^{-1}\right)\right): 400,433,560,642,740,759,849$, 950, 1022, 1072, 1223, 1280, 1380, 1458, 1603, 1628(C=N), 1652, 1699, 2412, 2843, 2942. UV-vis (nm (Abs)): (acetone) 346 (2.37). (methanol) 347 (0.30). (chloroform) 358 (0.52). CD (nm ( $\theta / \mathrm{mdeg})$ ): (acetone) 374 (-91.5), 490 (7.61), 598 (11.9). (methanol) 372 (-11.4), 491 (0.92), 606 (2.27). (chloroform) 389 (-25.4), 483 (2.21), 605 (4.32).

\subsubsection{Preparation of GdNi}

To a solution of $o$-vanillin $(0.3124 \mathrm{~g}, 2.00 \mathrm{mmol})$ dissolved in methanol (40 $\mathrm{mL})$, $(1 R, 2 R)-(-)-1,2$-cyclohexandiamine $(0.1358 \mathrm{~g}, 1.00 \mathrm{mmol})$ was added dropwise and stirred at $313 \mathrm{~K}$ for $2 \mathrm{~h}$ to give yellow solution of ligand. Nickel (II) acetate tetrahydrate $(0.2517 \mathrm{~g}, 1.00 \mathrm{mmol})$ was added to give rise to orange solution of the complex. After stirring for $2 \mathrm{~h}$, gadolinium (III) nitrate hexahydrate $(0.4640 \mathrm{~g}, 1.00 \mathrm{mmol})$ was added and refluxed at $373 \mathrm{~K}$ for $4 \mathrm{~h}$ to yield orange solution with orange precipitates. This crude orange compound was filtered and recrystallized from methanol/diethyl ether to give orange precipitates. Yield $0.5859 \mathrm{~g}(89.0 \%)$. IR $\left(\mathrm{KBr}\left(\mathrm{cm}^{-1}\right)\right): 419,452$, 565, 667, 739, 784, 856, 1033, 1076, 1164, 1232, 1308, 1380, 1471, 1508, 1619(C=N), 1652, 1699, 2412, 2831, 2928. UV-vis (nm (Abs)): (acetone) 331 (1.86). (methanol) 331 (0.46). (chloroform) 340 (0.65). CD (nm ( $\theta / \mathrm{mdeg})$ ): (acetone) 392 (-44.5), 444 (8.65), 555 (10.1). (methanol) 397 (-6.34), 458 (1.08), 555 (1.91). (chloroform) 404 (-13.6), 459 (2.41), 574 (3.55).

\subsubsection{Preparation of $\mathrm{GdCu}$}

To a solution of $o$-vanillin $(0.3022 \mathrm{~g}, 2.00 \mathrm{mmol})$ dissolved in methanol $(40 \mathrm{~mL})$, $(1 R, 2 R)$-(-)-1,2-cyclohexandiamine $(0.1143 \mathrm{~g}, 1.00 \mathrm{mmol})$ was added dropwise and stirred at $313 \mathrm{~K}$ for $2 \mathrm{~h}$ to give yellow solution of ligand. Copper (II) acetate monohydrate $(0.2089 \mathrm{~g}, 1.00 \mathrm{mmol})$ was added to give rise to purple-red solution of the complex. After stirring for $2 \mathrm{~h}$, gadolinium (III) nitrate hexahydrate $(0.4634 \mathrm{~g}, 1.00 \mathrm{mmol})$ was added and refluxed at $373 \mathrm{~K}$ for $4 \mathrm{~h}$ to yield red solution with red precipitates. This crude red compound was filtered and recrystallized from methanol/diethyl ether to give red precipitates. Yield $0.5220 \mathrm{~g}(78.0 \%)$. IR $\left(\mathrm{KBr}\left(\mathrm{cm}^{-1}\right)\right)$ : 430, 560, 667, 740, 758, 838, 949, 1020, 1072, 1165, 1222, 1303, 1374, 1460, 1527, 1605, 1624, 1652, 2420, 2842, 2924. 
UV-vis (nm (Abs)): (acetone) 346 (2.06). (methanol) 346 (2.04). (chloroform) 360 (0.79). $\mathrm{CD}$ (nm ( $\theta / \mathrm{mdeg})$ ): (acetone) 375 (-73.9), 483 (6.39), 569 (9.46). (methanol) 374 (-62.8), 487 (5.28), 604 (12.4). (chloroform) 397 (-35.6), 481 (3.47), 609 (1.94).

\subsection{Physical Measurements}

Infrared spectra were recorded as KBr pellets on a JASCO FT-IR 4200 plus spectrophotometer in the range of $4000-400 \mathrm{~cm}^{-1}$ at $298 \mathrm{~K}$. Absorption (and diffuse reflectance) electronic spectra were measured on a JASCO V-570 UV/VIS/NIR spectrophotometer (equipped with an integrating sphere) in the range of 800-200 $\mathrm{nm}$ at $298 \mathrm{~K}$. Circular dichroism (CD) spectra were measured on a JASCO J-820 spectropolarimeter in the range of 800-200 nm at $298 \mathrm{~K}$. Magnetic properties were investigated with a Quantum Design MPMS-XL superconducting quantum interference device magnetometer (SQUID). DC magnetic susceptibility data were measured at 5-300 K under 5000 Oe (measured at Institute for molecular Science and Institute for Solid State Physics, the University of Tokyo).

\subsection{X-ray Crystallography}

Orange prismatic single crystals of $\mathrm{NdNi}$ was glued on top of a glass fiber and coated with a thin layer of epoxy resin to measure the diffraction data. Intensity data were collected on a Bruker APEX2 CCD diffractometer with graphite monochromated Mo K $\alpha$ radiation $(\lambda=0.71073 \AA)$. Data analysis was carried out with a SAINT program package. The structures were solved by direct methods with a SHELXS-97 [40] and expanded by Fourier techniques and refined by full-matrix least-squares methods based on $F^{2}$ using the program SHELXL-97 [40]. An empirical absorption correction was applied by a program SADABS. All non-hydrogen atoms were readily located and refined by anisotropic thermal parameters. All hydrogen atoms were located at geometrically calculated positions and refined using riding models. Unfortunately, appropriate single crystals could not be obtained for other metal complexes.

Crystallographic data for $\mathrm{NdNi} . \mathrm{C}_{22} \mathrm{H}_{24} \mathrm{~N}_{5} \mathrm{NdNiO}_{13}$, crystal size $0.15 \mathrm{~mm} \times 0.13 \mathrm{~mm} \times 0.12 \mathrm{~mm}$, $\mathrm{M}_{\mathrm{w}}=769.41$, triclinic, space group $P 1, a=9.3035(11) \AA, b=12.1272(14) \AA, c=12.2122(14) \AA$, $\alpha=101.6500(10)^{\circ}, \beta=96.2000(10)^{\circ}, \gamma=90.0350(10)^{\circ}, V=1341.2(3) \AA^{3}, Z=2, D_{\text {calc }}=1.905 \mathrm{mg} / \mathrm{m}^{3}$, $\mathrm{F}(000)=766, \mathrm{R}_{1}=0.0224, \mathrm{wR}_{2}=0.0675$ (6137 reflections), $S=0.582$, Flack parameter $=-0.005(13)$. (where $\left.\mathrm{R}_{1}=\Sigma|| \mathrm{F}_{\mathrm{o}}|-| \mathrm{F}_{\mathrm{c}}|/ \Sigma| \mathrm{F}_{\mathrm{o}} \mid \mathrm{R}_{\mathrm{w}}=\left(\Sigma \mathrm{w}\left(\left|\mathrm{F}_{\mathrm{o}}\right|-\left|\mathrm{F}_{\mathrm{c}}\right|\right)^{2} / \Sigma \mathrm{w}\left|\mathrm{F}_{\mathrm{o}}\right|^{2}\right)^{1 / 2}, \mathrm{w}=1 /\left(\sigma^{2}\left(\mathrm{~F}_{\mathrm{o}}\right)+(0.1 \mathrm{P})^{2}\right), \mathrm{P}=\left(\mathrm{F}_{\mathrm{o} 2}+2 \mathrm{~F}_{\mathrm{c} 2}\right) / 3\right)$.

\section{Conclusions}

In summary, among four chiral $3 \mathrm{~d}-4 \mathrm{f}$ complexes reported herein, only $\mathrm{GdCu}$ was confirmed to be suitable for $\mathrm{CD}$ spectroscopy experiments in various environmental matrixes. In comparison with acetone solution and solid state CD spectra, the bands at about $470 \mathrm{~nm}$ in the solid state spectra could be assigned as a so-called artifact CD peak in the solid state. In this PMMA polymer matrixes system, that suggests anisotropic molecular orientation as well as restricted molecular motion, we have shown matrix viscosity-dependence of the intensity of artifact peaks resulting from chiroptical features of $3 \mathrm{~d}-4 \mathrm{f}$ complexes for the first time. Rigid matrix maintaining anisotropic orientation exhibited a decrease in intensity of the artifact $\mathrm{CD}$ peak toward negative $\theta$ values. 


\section{Supplementary Data}

CCDC 837663 contains the supplementary crystallographic data. These data can be obtained free of charge via http://www.ccdc.cam.ac.uk/conts/retrieving.html, or from the Cambridge Crystallographic Data Centre, 12 Union Road, Cambridge CB2 1EZ, UK; fax: +44-1223-336-033; or E-Mail: deposit@ccdc.cam.ac.uk.

\section{References}

1. Akitsu, T.; Einaga, Y. Syntheses, crystal structures, and electronic properties of a series of copper(II) complexes with 3,5-halogen-substituted Schiff base ligands and their solutions. Polyhedron 2005, 24, 2933-2943.

2. Akitsu, T.; Einaga, Y. Synthesis, crystal structures, and electronic properties of Schiff base nickel(II) complexes: towards solvatochromism induced by photochromic solute. Polyhedron 2005, 24, 1869-1877.

3. Akitsu, T. Photofunctional supramolecular solution systems of chiral Schiff base nickel(II), copper(II), and zinc(II) complexes and photochromic azobenzenes. Polyhedron 2007, 26, 2527-2535.

4. Akitsu, T.; Einaga, Y. Novel photo-induced aggregation behavior of a supramolecular system containing iron(III) magnetic ionic liquid and azobenzene. Inorg. Chem. Commun. 2006, 9, 1108-1110.

5. Akitsu, T.; Nishijo, J. The first observation of photoinduced tuning of AC magnetization for organic/inorganic hybrid materials composed of $\mathrm{Mn}_{12}$-acetate and azobenzene. J. Magn. Magn. Mater. 2007, 315, 95-100.

6. Akitsu, T.; Nishijo, J. The first detection of photomodulation by both DC and in-phase AC susceptibility for organic/inorganic hybrid materials containing cyano-bridged $\mathrm{Gd}-\mathrm{Cr}$ complex and azobenzene. J. Magn. Magn. Mater. 2008, 320, 1586-1590.

7. Akitsu, T. The tuning of quantum magnetization for organic/inorganic hybrid materials composed of Mn12-acetate and azobenzene casted into PMMA films on PVA films. J. Magn. Magn. Mater. 2008, 321, 207-212.

8. Akitsu, T.; Ishioka, C.; Itoh, T. Polarized Spectroscopy of Hybrid Materials of $\mathrm{Mn}_{12}$ Single-Molecule Magnet and Azobenzene or Disperse Red 1 in PMMA Films. Cent. Eur. J. Chem. 2009, 7, 690-696.

9. Akitsu, T.; Itoh, T. Polarized spectroscopy of hybrid materials of chiral Schiff base cobalt(II), nickel(II), copper(II), and zinc(II) complexes and photochromic azobenzenes in PMMA films. Polyhedron 2010, 29, 477-487.

10. Akitsu, T.; Ishioka, C. Manipulation and Observation by Polarized Light: Hybrid Materials of Chiral Schiff Base Mn(III) Complexes and Azobenzene in PMMA. Asian Chem. Lett. 2010, 14, 37-51.

11. Aritake, Y.; Takanashi, T.; Yamazaki, A.; Akitsu, T. Polarized spectroscopy and hybrid materials of chiral Schiff base $\mathrm{Ni}(\mathrm{II}), \mathrm{Cu}(\mathrm{II}), \mathrm{Zn}(\mathrm{II})$ complexes with included or separated azo-groups. Polyhedron 2011, 30, 886-894.

12. Akitsu, T.; Miura, Y. Polarized electronic spectra of organic/inorganic hybrid materials of chiral Schiff base $\mathrm{Ni}(\mathrm{II})$ or $\mathrm{Cu}(\mathrm{II})$ complexes and disperse red 1 or azobenzene in PMMA films. J. Chem. Chem. Eng. 2011, 5, 443-450. 
13. Akitsu, T.; Tanaka, R. Polarized Electronic and IR Spectroscopy of Hybrid Materials of Chiral $\mathrm{Cu}(\mathrm{II})$ and $\mathrm{Mn}_{12}$ Complexes and Some Photochromic Compounds in PMMA Films. Asian Chem. Lett. 2010, 14, 235-254.

14. Akitsu, T.; Tanaka, R. Polarized Electronic and IR Spectra of Hybrid Materials of Chiral Mn(II) Complexes and Different Types of Photochromic Dyes Showing Photoisomerization or Weigert Effect. Curr. Phys. Chem. 2011, 1, 82-89.

15. Akitsu, T.; Yoshida, A. Detection of Intermolecular Interaction Between Pd(II) Complexes Having Imidate and Amine Ligands and Photochromic Dyes in Hybrid Solution Systems by Absorption and Fluorescence Spectra. Curr. Phys. Chem. 2011, 1, 76-81.

16. Kuroda, R.; Harada, T.; Shindo, Y. A solid-strate dedicated circular dichroism spectrophotometer: Development and application. Rev. Sci. Instr. 2001, 72, 3802-3810.

17. Schellaman, J.; Jensen, H.P. Optical spectroscopy of oriented molecules. Chem. Rev. 1987, 87, 1359-1399.

18. Tinoco, I.; Mickols, W.; Maestre, M.F.; Bustamante, C. Absorption, scattering, and imaging of biomolecular structures with polarized light. Annu. Rev. Biophys. Biophys. Chem. 1987, 16, 319-349.

19. Claborn, K.; Isborn, C.; Kaminsky, W.; Kahr, B. Optical rotation of achiral comounds. Angew. Chem. Int. Ed. Engl. 2008, 47, 5706-5717.

20. Kaminsky, W. Experimental and phenomenological aspects of circular birefringence and related properties in transparent crystals. Rep. Prog. Phys. 2000, 63, 1575-1640.

21. Shindo, Y.; Nakagawa, M. On the artifacts in circularly polarized emission spectroscopy. Appl. Spectrosc. 1985, 39, 32-38.

22. Shindo, Y.; Nakagawa, M.; Ohmi, T. On the problems of CD spectropolarimeters.II: artifacts in CD spectrometers. Appl. Spectrosc. 1985, 39, 860-868.

23. Hipps, K.W.; Crosby, G.A. Applications of the photoelastic modulator to polarization spectroscopy. J. Phys. Chem. 1979, 83, 555-562.

24. Goldstein, D.H. Polarized Light; Marcel Drekker: New York, NY, USA, 2003.

25. Kobayashi, J.; Uesu, Y.; Takehara, H. A new optical method and apparatus "HAUP" for measuring simultaneously optical activity and birefringence of crystals. II. Application to triglycine-sulphuric acid $\left(\mathrm{NH}_{2} \mathrm{CH}_{2} \mathrm{CO}_{2} \mathrm{H}\right)_{3} . \mathrm{H}_{2} \mathrm{SO}_{4}$. J. Appl. Crystallogr. 1983, 16, 212-219.

26. Kaminsky, W.; Claborn, K.; Kahr, B. Polarimetric imaging of crystals. Chem. Soc. Rev. 2004, 33, 514-525.

27. Kahr, B.; Bing, Y.; Kaminsky, W.; Viterbo, D. Turinese stereochemistry: Eligio Perucca's enantioselectivity and Primo Levi's asymmetry. Angew. Chem. Int. Ed. 2009, 48, 3744-3748.

28. Bing, Y.; Selassie, D.; Paradise, R.H.; Isborn, C.; Kramer, N.; Sadilek, M.; Kaminsky, W.; Kahr, B. Circular dichroism tensor of a triarylmethyl propeller in sodium chlorate. J. Am. Chem. Soc. 2010, 132, 7454-7465.

29. Kaminsky, W.; Geday, M.A.; Herreros-Cedrés, J.; Kahr, B. Optical rotatory and circular dichroic scattering. J. Phys. Chem. A 2003, 107, 2800-2807.

30. Kaminsky, W.; Herreros-Cedrés, J.; Geday, M.A.; Kahr, B. Dispersion of anomalous azimuthal rotation and circular extinction contrast in dyed $\mathrm{K}_{2} \mathrm{SO}_{4}$ crystals. Chirality 2004, 16, S55-S61. 
31. Claborn, K.; Chu, A.S.; Jang, S.H.; Su, F.Y.; Kaminsky, W.; Kahr, B. Circular extinction imaging: determination of the absolute orientation of embedded chromophores in enantiomorphously twinned $\mathrm{LiKSO}_{4}$ crystals. Cryst. Growth Des. 2005, 5, 2117-2123.

32. Hazra, S.; Koner, R.; Nayak, M.; Sparkes, H.A.; Howard, J.A.K.; Mohanta, S. Cocrystallized dinuclear-mononuclear $\mathrm{Cu}_{3}{ }_{3} \mathrm{Na}^{\mathrm{I}}$ and double-decker-triple-decker $\mathrm{Cu}_{5}{ }_{5} \mathrm{~K}_{3}^{\mathrm{I}}$ complexes derived from N,N'-Ethylenebis(3-ethoxysalicylaldimine). Cryst. Growth Des. 2009, 9, 3603-3608.

33. Akine, S.; Taniguchi, T.; Nabeshima, T. Cooperative formation of trinuclear Zinc(II) complexes via complexation of a tetradentate oxime chelate ligand, salamo, and Zinc(II) acetate. Inorg. Chem. 2004, 43, 6142-6144.

34. Jana, A.; Majumder, S.; Carrella, L.; Nayak, M.; Weyhermueller, T.; Dutta, S.; Schollmeyer, D.; Rentschler, E.; Koner, R.; Mohanta, S. Syntheses, structures, and magnetic properties of diphenoxo-bridged $\mathrm{Cu}^{\mathrm{II}} \mathrm{Ln}^{\mathrm{III}}$ and $\mathrm{Ni}^{\mathrm{II}}$ (Low-Spin) $\mathrm{Ln}^{\mathrm{III}}$ compounds derived from a compartmental ligand $(\mathrm{Ln}=\mathrm{Ce}-\mathrm{Yb})$. Inorg. Chem. 2010, 49, 9012-9025.

35. Andruh, M.; Costes, J.P.; Diaz, C.; Gao, S. 3d-4f combined chemistry: synthetic strategies and magnetic properties. Inorg. Chem. 2009, 48, 3342-3359.

36. Burrow, C.E.; Burchell, T.J.; Lin, P.H.; Habib, F.; Wernsdorfer, W.; Clerac, R.; Murugesu, M. Salen-Based $\left[\mathrm{Zn}_{2} \mathrm{Ln}_{3}\right]$ complexes with fluorescence and single-molecule-magnet properties. Inorg. Chem. 2009, 48, 8051-8053.

37. Yang, X.P.; Jones, R.A.; Wong, W.K.; Lynch, V.; Oye, M.M.; Holmes, A.L. Design and synthesis of a near infra-red luminescent hexanuclear Zn-Nd prism. Chem. Commun. 2006, 1836-1838.

38. Wong, W.K.; Yang, X.; Jones, R.A.; Rivers, J.H.; Lynch, V.; Lo, W.K.; Xiao, D.; Oye, M.M.; Holmes, A.L. Multinuclear luminescent schiff-base $\mathrm{Zn-Nd} \mathrm{sandwich} \mathrm{complexes.} \mathrm{Inorg.} \mathrm{Chem.}$ 2006, 45, 4340-4345.

39. Pasatoiu, T.D.; Madalan, A.M.; Kumke, M.U.; Tiseanu, C.; Andruh, M. Temperature switch of lmct role: from quenching to sensitization of europium emission in a $\mathrm{Zn}^{\mathrm{II}}-\mathrm{Eu}^{\mathrm{III}}$ binuclear complex. Inorg. Chem. 2010, 49, 2310-2315.

40. Sheldrick, G.M. A short history of SHELX. Acta Cryst. A 2007, 64, 112-122.

(C) 2011 by the authors; licensee MDPI, Basel, Switzerland. This article is an open access article distributed under the terms and conditions of the Creative Commons Attribution license (http://creativecommons.org/licenses/by/3.0/). 